Amera K Khalil

BDS, MSc (Lect)

\section{Panoramic Radiography, Diagnosis and Abnormalities.}

\author{
Department of Oral and Maxillofacial Surgery \\ College of Dentistry, Medical Hawler University
}

\begin{abstract}
Aim: To find the importance of panoramic radiograph as aid in diagnosis, prognosis and determination of treatment complexity.Materials and Methods: This study was conducted among (132) panoramic radiographs of males and females which were nearly equal in numbers. The mean age of males was (36.73) years and the mean age of the females was ( 29.82) years. Result: Among these radiographs (0.75\%) showed edentulous upper and lower ridges, ( $0.75 \%$ ) showed multiple dental implants, (1.51\%) showed fixative appliance, ( $8.33 \%$ ) showed fixed bridges, (9.84\%) showed retained roots, (16.66\%) showed endodontically treated teeth, (5.3\%) showed radiopaque lesions. The dental caries experience of the total patients were (6.92) for $\mathrm{D}_{3} \mathrm{MFT}$ and (4.07) for $\mathrm{D}_{3} \mathrm{FS}$. The majority of caries experience was found in permanent molars. The percentage of radiograph that showed microdontia and congenital missing teeth were (4.54\%) and (10.6\%) respectively, the number of males was higher than that of females and mostly related to third molars. The percentage of hyperdontia $(0.75 \%)$, dilacerations $(4.54 \%)$, concrescence $(0.75 \%)$. The number of impacted teeth in females was higher than that in males with statistically significant difference. Conclusion:The panoramic survey is necessary for all patients.
\end{abstract}

Key wards: Panoramic Radiography, Dental caries, Implants, Impacted teeth.

Khalil AK. Panoramic Radiography, Diagnosis and Abnormalities. Al-Rafidain Dent J. 2008; 8(2): 205-212

Received: 5/6/2007_Sent to Referees: 5/6/2007

Accepted for Publication: 11/11/2007

\section{INTRODUCTION}

The radiographic examination for patients generally performed after clinical examination for detection of dental caries, periodontal diseases, cysts, developmental abnormalities of the teeth and jaws, and bony infections or tumors ${ }^{(1,2)}$. A full mouth series of periapical radiographs, occlusal, panoramic or other extraoral radiographs may be used to achieve diagnostic and therapeutic goals ${ }^{(3,4)}$. Holes in teeth are the result of our modern diet. A certain type of microbe feeds sugars, excreting acids that bore into enamel.. After a hole is formed in a tooth, the acid - generating bacteria live in it and continue their dirty work and eventually they make the cavity worse ${ }^{(5)}$. The clinical caries diagnostic criteria used for caries study examinations are $^{(6)}$ :

0- Surface of tooth sound.

1- Initial caries (staining,discolouration, or rough spots in the enamel).

2- Enamel caries (demonstrable loss of tooth surface but is no evidence that the lesion has penetrated the dentine.

3- Caries of dentine.

4- Pulp involvement.

The majority of the disease was to be found in the molar teeth, particularly the first permanent molars, and the majority of caries experience, both restored and unrestored was found in the occlusal surfaces of teeth ${ }^{(7)}$.

A panoramic radiograph is superior to periapical $\mathrm{x}$-rays in its coverage when the removal of third molars is planned., which are common surgical procedures among young adults. The third molars classified according to impaction types into erupted, partially erupted and unerupted, and also classified according to the angulations of the tooth into vertical, mesioangular, distoangular and horizontal ${ }^{(8)}$. The impacted mandibular canines are less common than impacted maxillary canines, they are often in a horizontal position and can migrate anteriorly, some crossing the midline. A 
canine is considered transmigrated when more than half of the tooth has crossed the midline ${ }^{(9)}$.

Developmental disturbances of teeth can appear in the size like macrodontia and microdontia, number like hypodontia, anodontia and supernumerary teeth, form and structure of teeth ${ }^{(10)}$.

The aim of this study was to find the importance of panoramic radiograph as aid in diagnosis, prognosis and determination of treatment complexity.

\section{MATERIAL AND METHOD}

This study was based on examination of (132) panoramic (O.P.G) view (Diamax digital radiographic unit) for patients with age range $(13-68)$ years. The name, age and sex of each patient were recorded. The radiographs were examined by two radiologists and the radiographic observations were added to the study form and the results were analyzed.

\section{RESULTS}

The total number of patients were (132). Approximately half of the sample was males and the another half was females ( males $=65$, females $=67$ ). The mean age of the males was (36.73) years, and the mean age of the females was (29.82) years.

One radiograph $(0.75 \%)$ showed edentulous upper and lower alveolar ridges of females (63) years old, and one radiograph $(0.75 \%)$ showed edentulous upper alveolar ridge with multiple dental implants in (50) years old male ( Figure 1).

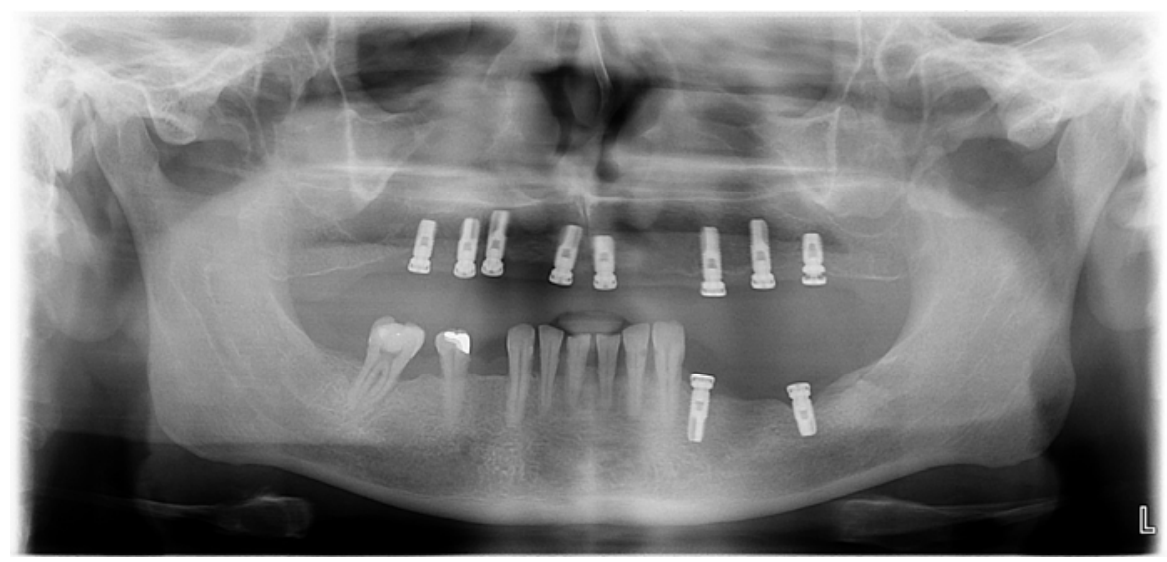

Figure (1): Multiple implants in the jaws of (50) years old male.

Two radiographs (1.51\%) showed fixative appliance, one is intra osseous for fractured lower jaw, and one for fixation of the upper anterior teeth by dental wire as seen in (Figure 2,3).

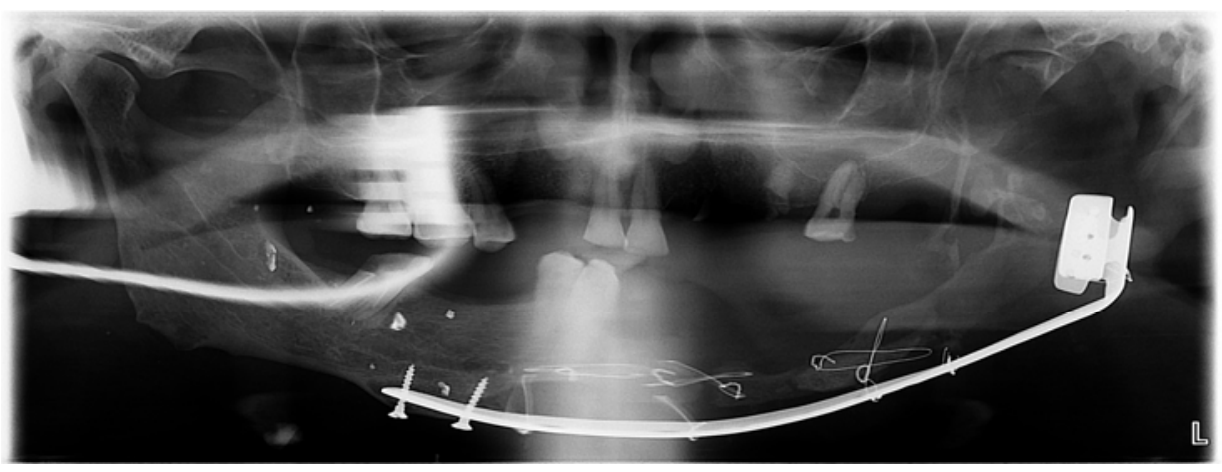

Figure (2): Intra-osseous fixative Appliances in the jaws of (50) years old male. 


\section{Panoramic Radiography}

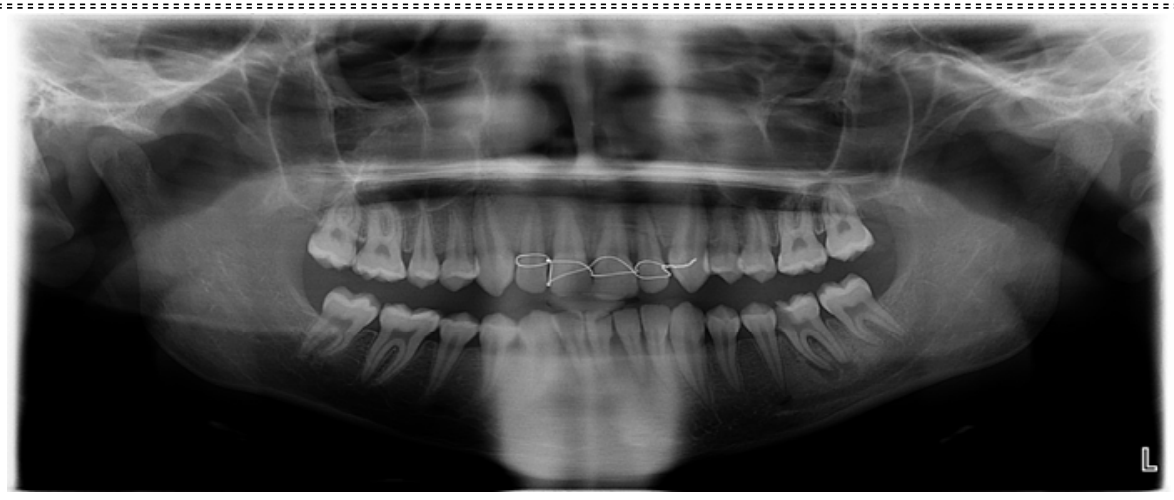

Figure (3): Fixation of upper anterior teeth of (16) years old male.

The total number of patients that have bridges were (11) patients (8.33\%), the number of females were (9) patients with mean age of (36.44) years and the number of their bridge units was (80) units. One female only had upper and lower bridges that cover all upper and lower teeth with
(28) bridge units (Figure 4), while the other females had a range of $(2-10)$ bridge units. The number of males was (2) patients with mean age of (61) years, one patient had (10) bridge units and the other had (7) bridge units.

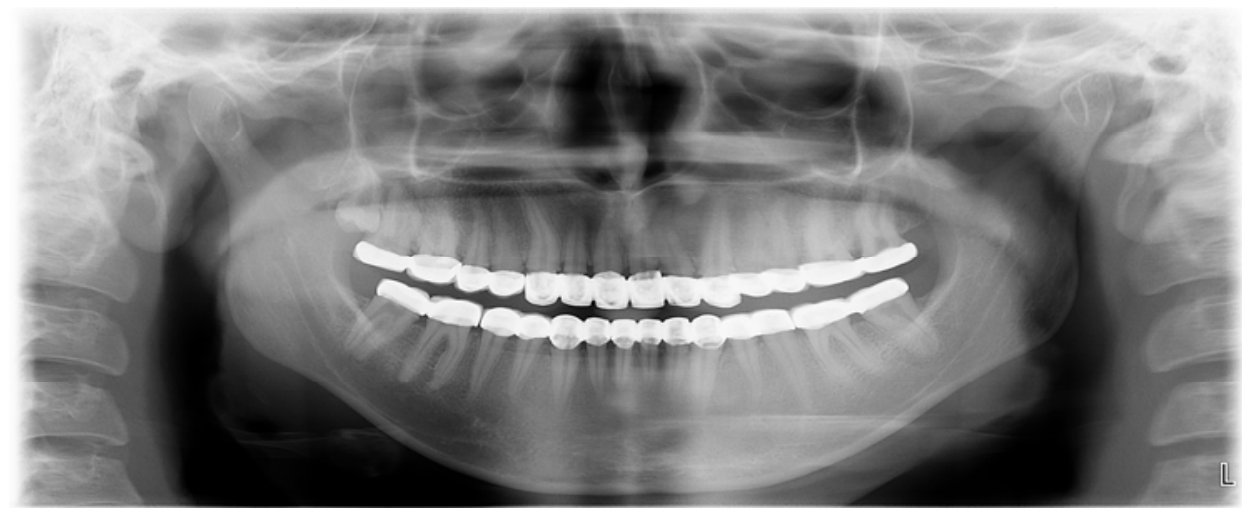

Figure (4): Upper and lower bridges of (34) years old female.

\section{Dental caries experience:}

The dental caries experience of total patients was recorded to be (6.92) for $\mathrm{D}_{3} \mathrm{MFT}$ and (4.07) for D3FS. The $\mathrm{D}_{3} \mathrm{MFT}$ for males was (6.38) while for females was (7.46). Statistically significant difference was seen between males and females $(P<$ 0.06 ) in relation to $\mathrm{D}_{3} \mathrm{MFT}$. The missing, decayed and filling fraction in males were less than that of females and the number of missing upper teeth in males and females were higher than that of lower, while the decayed and filled upper teeth in females were higher than that of lower teeth, while in males they were nearly equals. The majority of caries experience $\mathrm{D}_{3} \mathrm{MFT}$ was found in the permanent molars (figure 6). The $\mathrm{D}_{3} \mathrm{FS}$ for males was (3.61), while for females was (4.53). Statistically significant difference was seen between males and females $(\mathrm{P}<0.01)$ in relation to
$\mathrm{D}_{3} \mathrm{FS}$. The DS and FS in males was less than that of females and the majority of caries experience $\mathrm{D}_{3} \mathrm{FS}$ both restored and unrestored was found in the occlusal surfaces of teeth (figure 7).

Disturbances of teeth:

The number of radiographs that showed microdontia were (16) and represent $(4.54 \%)$, two patients were females (1.51\%), one with bilateral small upper lateral incisors and the other with bilateral small upper third molars. Four patients were males (3.03\%), one with bilateral small upper lateral incisors and upper third molars, the second with bilateral small upper third molars, and the rest had small upper right third molars only. The number of upper third molars with microdontia was higher than that of lateral incisors (Figure 8). 
Khalil AK.

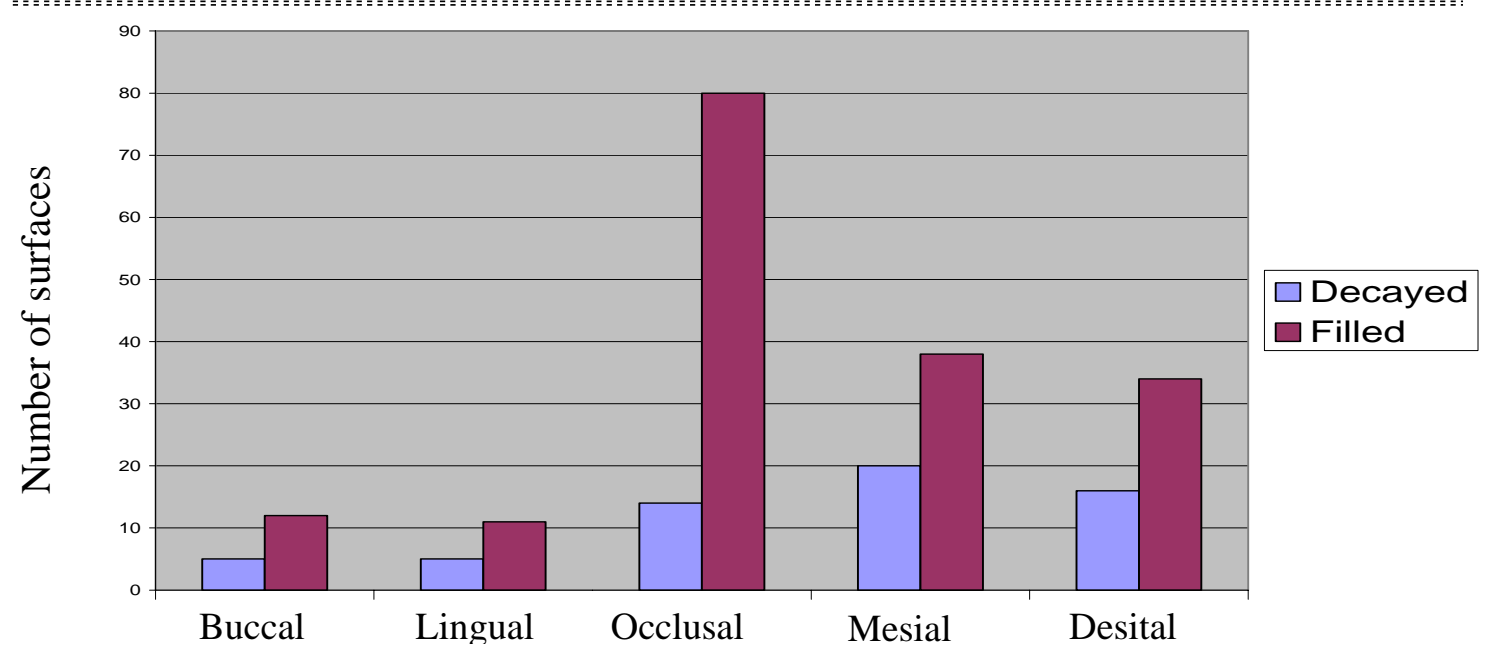

Figure (6): Distribution of caries experience by surface $\left(\mathrm{D}_{3} \mathrm{FS}\right)$, radiographic examination data only for Males.

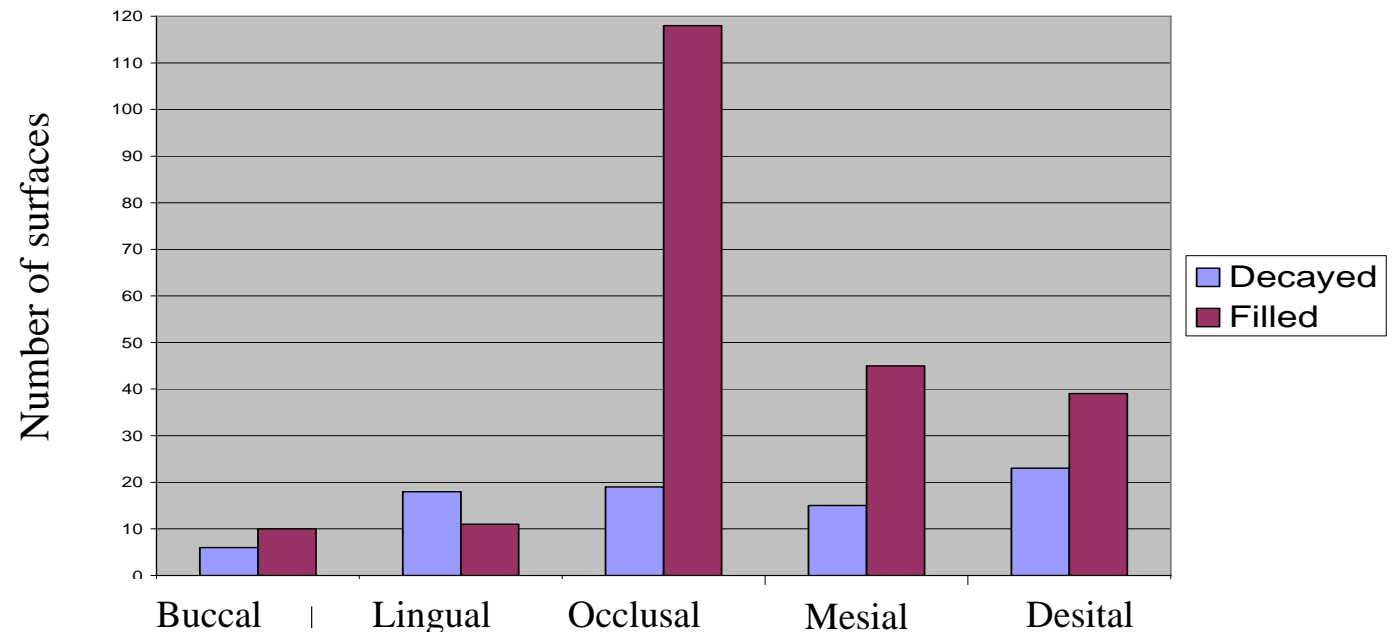

Figure (7): Distribution of caries experience by surface $\left(\mathrm{D}_{3} \mathrm{FS}\right)$, radiographic examination data only for Females.

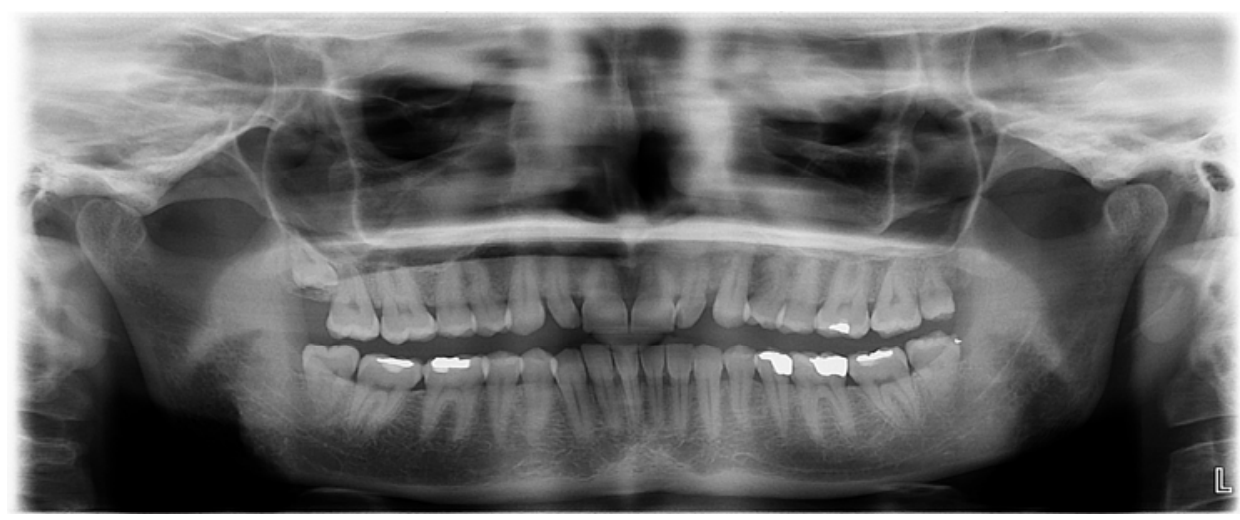

Figure (8): Microdontia of upper lateral Incisors of (34) years old female.

The number of radiograph that showed congenital missing teeth were (41) with percentage $(10.6 \%)$. The number of congenital missing teeth in males was (30) 
while in females was (11). The highest number of congenital missing teeth was related to third molars (31), followed by second premolars (9), and then second mo- lar (1), (Figure 9). One radiographs $(0.75 \%)$ showed hyperdontia, with supernumerary upper fourth molar (figure 10).

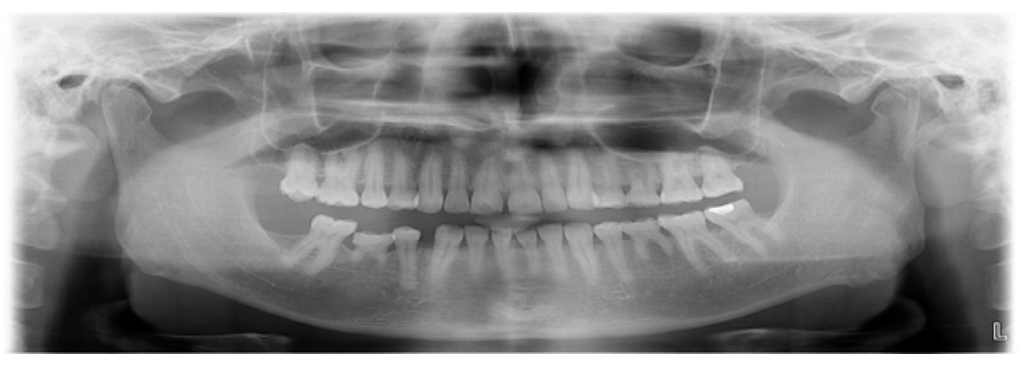

Figure (9): Congenital missing of third molars, lower right second molar, upper left second premolar, and lower second right premolars. Note the ankylosis of three primary molar teeth of (44)years old male.

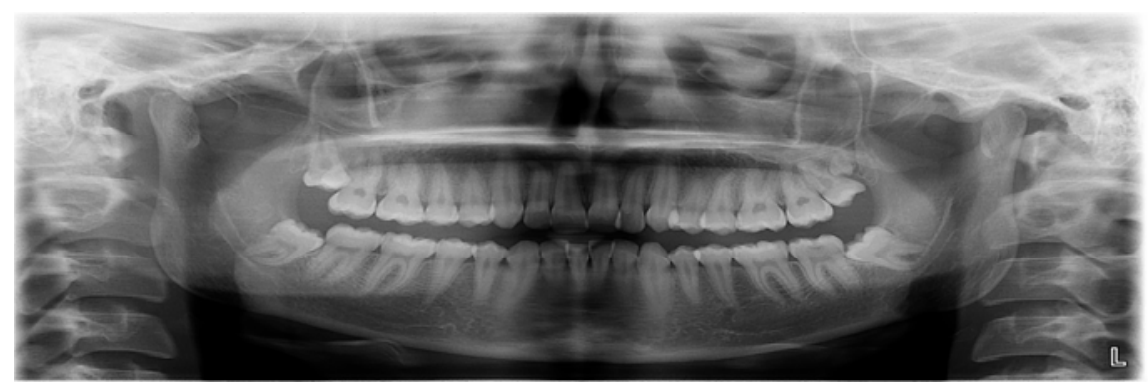

Figure (10): Impacted supernumerary microdont fourth molar of (22) years old female.

The total number of radiographs that showed dilacerations were (6) with percentage of $(4.54 \%)$, four of them associated with lower third molars, one with lower canine, and one with upper first premolars (Figure 11). One radiograph (0.75\%) showed concrescence (Figure 12).

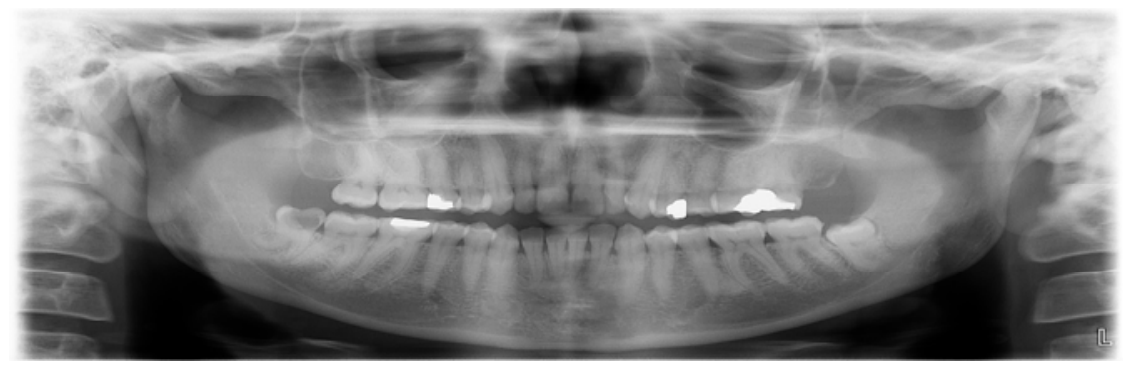

Figure (11): Dilaceration or extraordinary curving of lower right third molar root of (42) years old female.

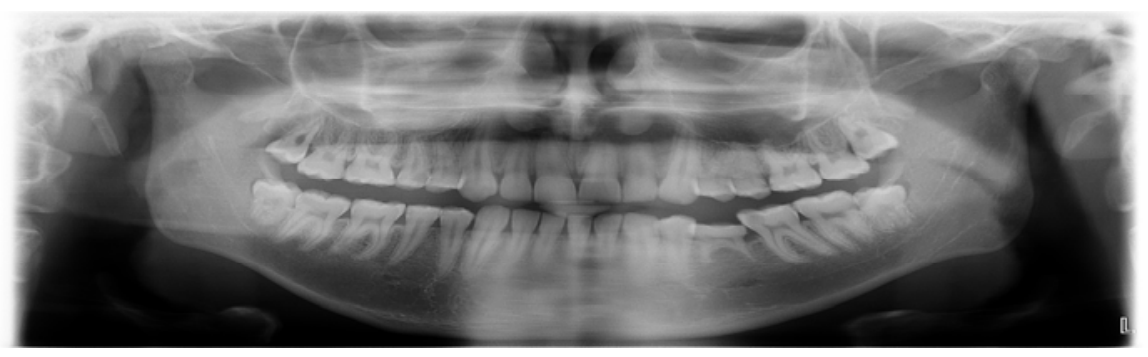

Figure 12: Concrescence in which the upper left first and second premolars are joined by cementum in (19) years old male. 
The number of radiographs of patients with age range of (22-68) years that showed impaction of third molars was (16) with percentage (12.12\%). The number of erupted third molars in males was higher than that of females, while the number of partially erupted and unerupted third molar in males was less than that of females. Statistically significant difference was seen between males and females ( $P<$ 0.01 ), most of the unerupted third molars in females had vertical angulation, while in males had mesioangular angulation (Figure 13,14).

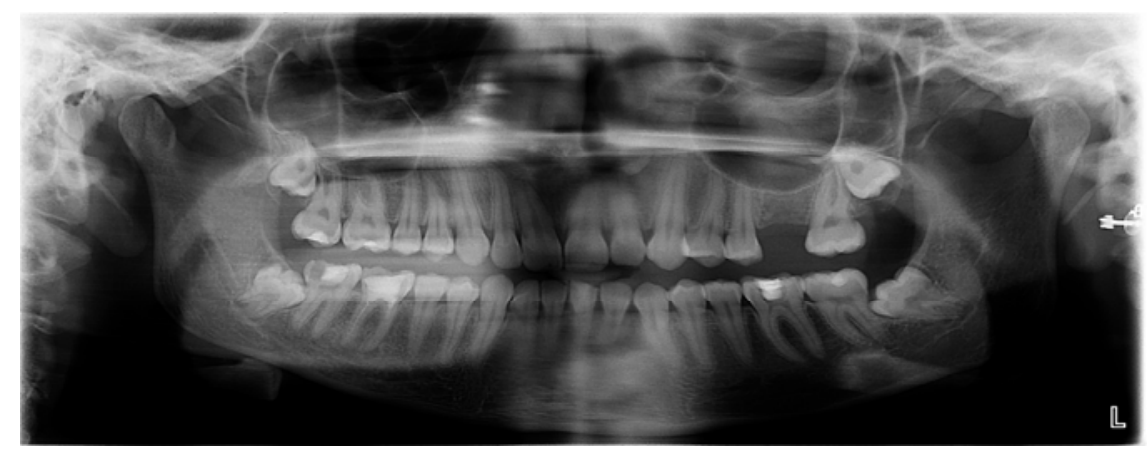

Figure (13): Three impacted and one partially erupted third molars of (22) years old male.
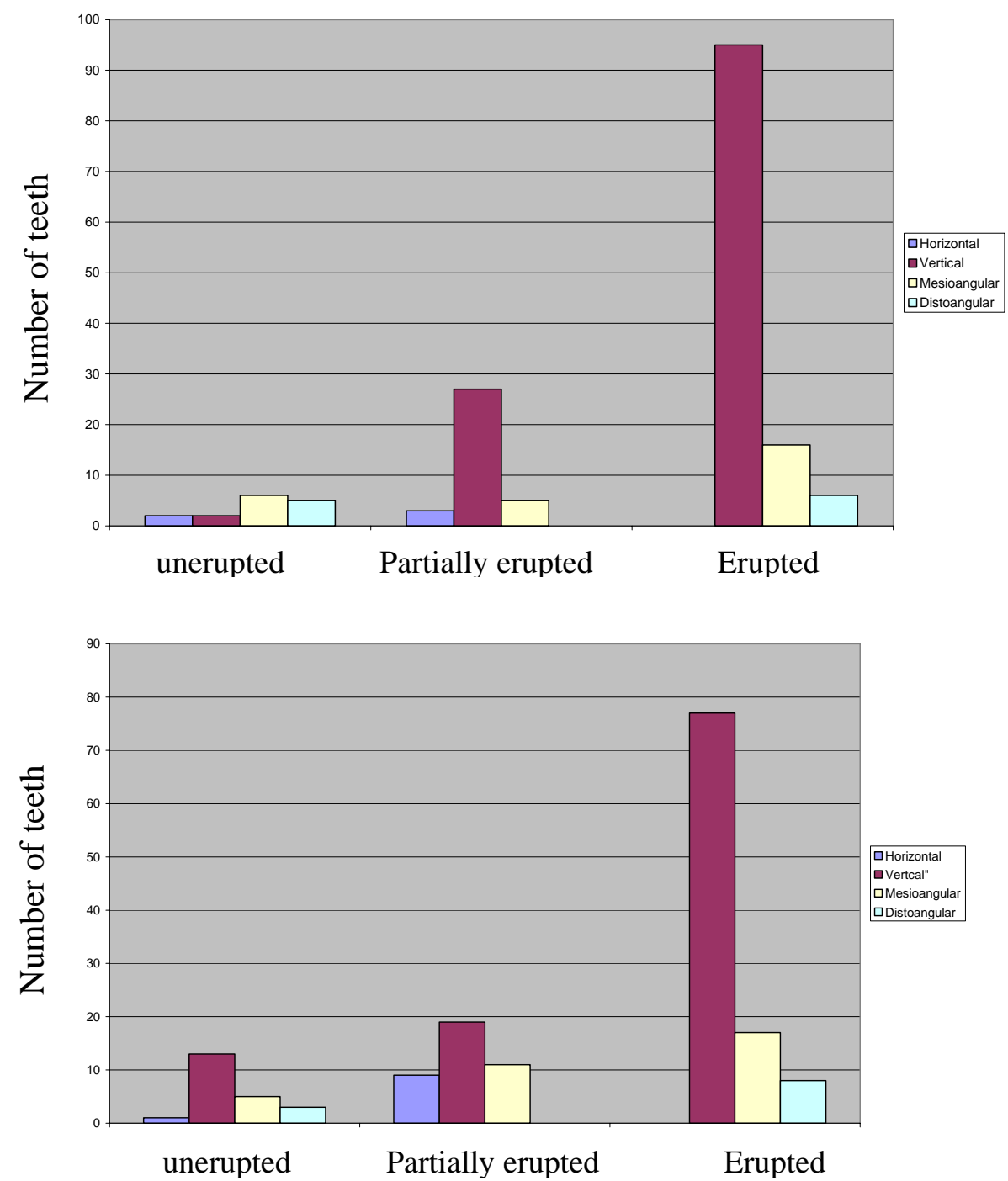

Figure (14): Distribution of the third molars according to the angulation of the tooth. Male (Upper diagram). Females (lower diagram). 
The number of patients with impacted canines in males was (2) and representing (1.51\%), two teeth were upper canines and two teeth were lower canines, while the number of patients with impacted canines in females was (8) and representing $(6.06 \%)$, eight teeth were upper canines and three teeth were lower canines, one case only $(0.75 \%)$ showed impacted lower left second premolar (Figure 15,16).

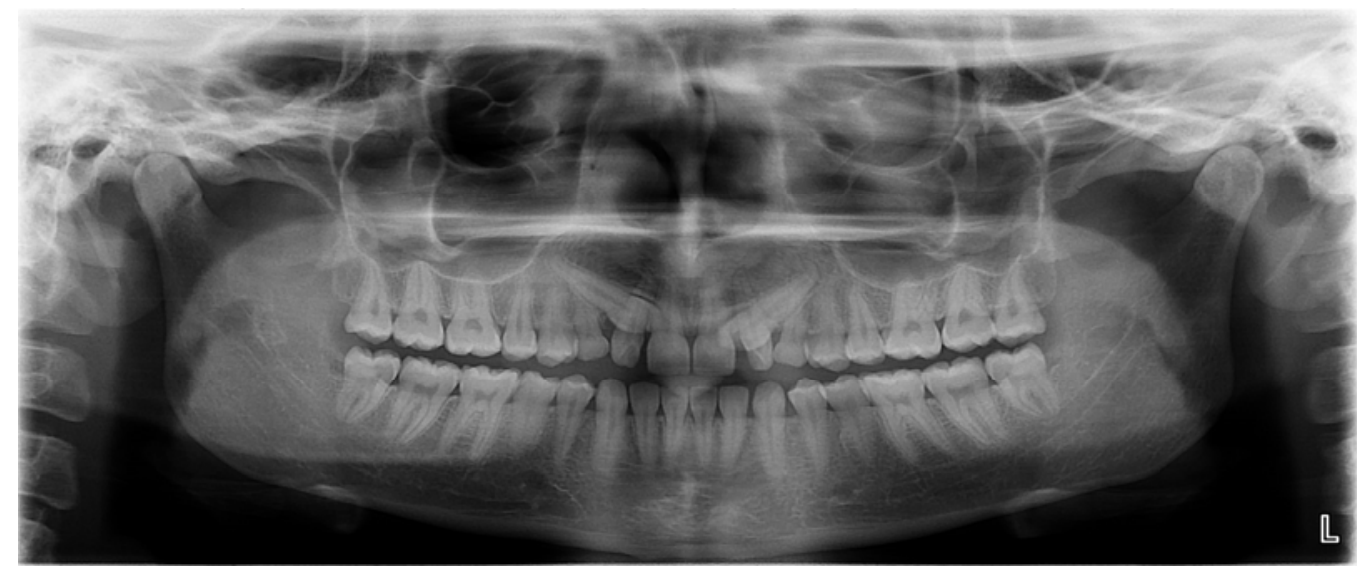

Figure (15): Impaction of upper canines of (24) years old female.

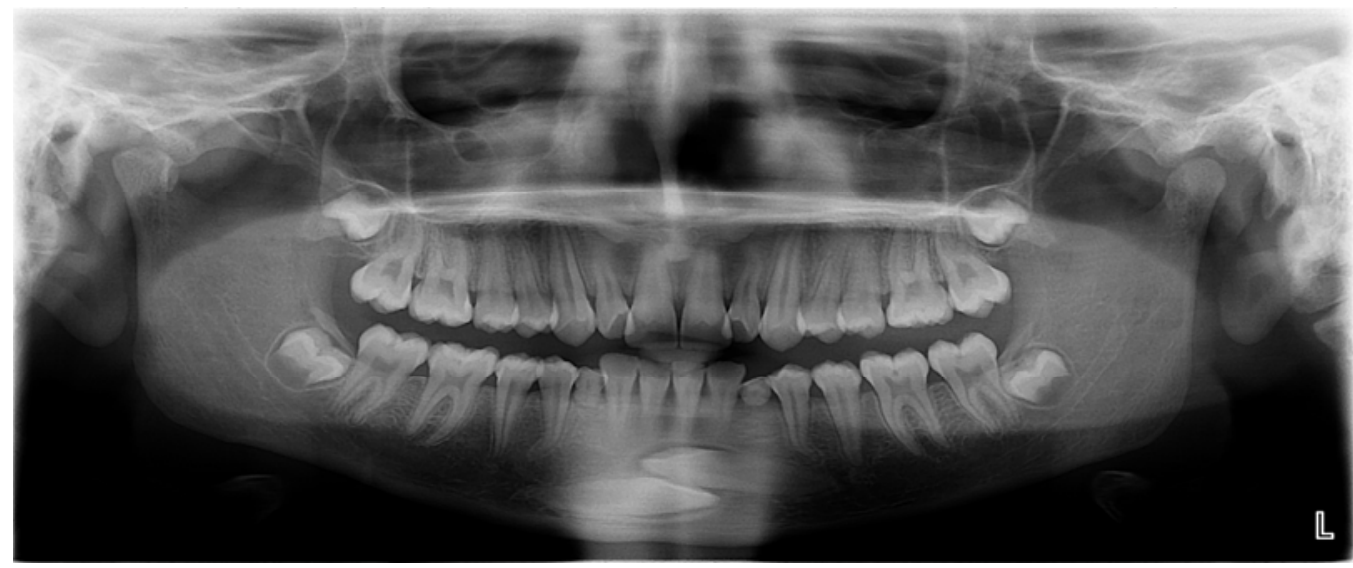

Figure (16): Impaction of lower canines of (14) years old female.

\section{DISCUSSION}

Among (132) patients surveyed by panoramic radiography, the dental caries experience of total patients were recorded to be (6.92) for $\mathrm{D}_{3} \mathrm{MFT}$ and (4.07) for $\mathrm{D}_{3} \mathrm{FS}$. The $\mathrm{D}_{3} \mathrm{MFT}$ and $\mathrm{D}_{3} \mathrm{FS}$ for males were less than that of females, while others (11) found that caries experience of their studied sample was recorded to be (5.41) for DMFT and (6.87) for DMFS and the values for females were higher than that of males.

The percentage of impacted teeth in this surveyed cases was (25\%), this may be due to the fact that most patients were young age and this was much higher if compared with the $(4.1 \%)$ of the study conducted by American Dental Associa- tion ${ }^{(12)}$ and $(6.3 \%)$ of the study conducted by others ${ }^{(13)}$.

The result also showed that the percentage of impacted upper and lower canines were $(7.56 \%)$ and $(3.78 \%)$ respectively, while others ${ }^{(14)}$ found that the percentage of impacted upper and lower canines were $(1.28 \%)$ and $(0.08 \%)$ respectively. Figures (14) showed that few angulations, other than vertical, erupted and this result is in agreement with others ${ }^{(15,16)}$

The percentage of congenitally missing teeth in this study was (10.6\%), higher percentage was seen in males than females, while others ${ }^{(10)}$ found that hypodontia forms about (10.6\%) of population and common in females. Both studies 
found that third molars were most frequently involved.

Relatively high number of retained roots or root fragments were detected in the present study and in other studies ${ }^{(3)}$. This could be due to bad dental management or negligence of the patients.

As observed (12.12\%), of cases in the present study showed periapical radiolucency (abscess or granuloma). Different findings were reported by other investigators ${ }^{(3)}$.

\section{CONCLUSION}

It is concluded that dentists should ask for panoramic radiography prior to treatment of their patients..

\section{REFERENCES}

1. Kantor M, Slom B. Efficacy of panoramic radiography in dental diagnosis and treatment planning. $J$ Dent Res. 1989; 68: 810 - 812 .

2. Monsour P. Getting the most from rotational panoramic radiographs. Aus Dent J. 2000; 45:136 - 142.

3. Rushton V, Horner K, Worthington $\mathrm{H}$. Routine panoramic radiography of new adults in general practice, relevance of diagnostic yield to treatment and identification of radiographic selection criteria. Oral Surg, Oral Pathol Oral Radiol Endod. 2002; 93: 488-495.

4. Molarder B. Panoramic radiography in dental diagnostics. Swed Dent J 1996; 119: 1-26.

5. Pitts NB. Susceptibility To Cavities. Diagnosis - me.com. (2004); 1-7.

6. Pitts NB, Fuffy HF, Nugent Z, Smit P. Dental epidemiological programme. Report of the 1992/1993 survey of 12 year old children. University of Dundee., Dundee, UK. 1993.

7. Deery HE, Fuffy NM, Nuttal ZJ, Nugent
Z, Pitts NB. The dental caries status of Scottish adolescents reported to be regular attenders. Initial results from a primary dental are based research network. Br Dent J. 1999; 187: 95 - 100.

8. Venta H, Murtoma L, Turtula J, Murma P, Paavalnimi YI. Assessing the eruption of lower third molars on the basis of radiographic features. Br J Oral Maxillofac Surg. 1991; 29: 259-262.

9. Mark M, Lawrence B. Extraction of a horizontally impacted mandibular canine through a genioplasty. J Oral Maxillofac Surg. 1996; 54: 1240 - 1242.

10. Soames JV, Southam JC (Eds). Disorders of development of teeth and craniofacial anomalies. In: Oral Pathology. $4^{\text {th }}$ ed,Oxford. 2005; 1-16.

11. Al - Zahawi SM, Al - Refai AS. The relationship between Calcium, Magnesium and Inorganic Phosphate of Human Mixed Saliva and Dental Caries. M.Sc. Thesis, College of Dentistry. Medical Hawler University. 2005.

12. American Dental Association (ADA). The relation of patients for dental radiographic examinations. 2004; 6: $15-16$.

13. Mahdizade M, Seyedmir H: The survey of panoramic radiographic findings in Isfahan City. J Isfahan Dent School. 2005; 1: $63-65$

14. Kramer RM, Williams AC. The incidence of impacted teeth. A survey at Harlem hospital. Oral Surg. 1985; 29: 430-432.

15. Haavikko K, Aitoneu M, Mattila $T$. Predicting angulation development and eruption of the lower third molar. Angle Orthodontist. 1998; 48: $39-41$.

16. Shillerw S. Positional changes in mesio - angular impacted mandibular third molars during a year. $J$ Am Dent Assoc. 1979; 99: $460-462$. 